\title{
Control of nausea with palonosetron versus granisetron, both combined with dexamethasone, in patients receiving cisplatin- or anthracycline plus cyclophosphamide-based regimens
}

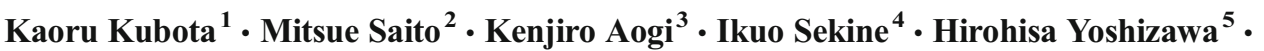 \\ Yasuhiro Yanagita $^{6} \cdot$ Hiroshi Sakai $^{7} \cdot$ Kenichi Inoue $^{8} \cdot$ Chiyoe Kitagawa $^{9}$. \\ Takashi Ogura ${ }^{10}$
}

Received: 25 January 2016 / Accepted: 28 March 2016 / Published online: 29 April 2016

(C) The Author(s) 2016. This article is published with open access at Springerlink.com

\begin{abstract}
Purpose In a comparative phase 3 study involving 1114 Japanese patients receiving highly emetogenic chemotherapy (HEC), palonosetron (PALO) was found to be superior to granisetron (GRA) for the prophylaxis of chemotherapy-induced nausea and vomiting (CINV) in the delayed phase. This post hoc analysis of the phase 3 study evaluated the efficacy of PALO for the control of nausea.

Methods The proportion of patients without nausea was assessed at 24-h intervals during the acute phase (0-24 h), delayed phase (24-120 h), and overall (0-120 h). No nausea rates were also evaluated by sex, type of chemotherapy (cisplatin or doxorubicin/epirubicin plus cyclophosphamide $[\mathrm{AC} / \mathrm{EC}]$ ), and age ( $<55$ vs. $\geq 55$ years). Nausea severity was categorized using a 4 -point Likert scale $(0=$ no nausea to $3=$ severe nausea $)$.

Results The proportion of patients without nausea was significantly higher in the PALO arm than in the GRA arm in the
\end{abstract}

Presented in part at the 35th Annual Meeting of the European Society of Medical Oncology, 2010, Milan.

Kaoru Kubota

kkubota@nms.ac.jp

1 Department of Pulmonary Medicine and Oncology, Graduate School of Medicine, Nippon Medical School, 1-1-5 Sendagi, Bunkyo-ku, Tokyo 113-8603, Japan

2 Department of Breast Oncology, Juntendo University Hospital, Tokyo, Japan

3 Department of Breast Oncology, National Hospital Organization Shikoku Cancer Center, Ehime, Japan

4 Division of Internal Medicine and Thoracic Oncology, National Cancer Centre Hospital, Tokyo, Japan delayed phase (37.8 \% vs. $27.2 \% ; p=0.002)$ and overall ( $31.9 \%$ vs. $25.0 \% ; p=0.0117)$. When analyzed by stratification factors, the proportion of patients without nausea was significantly higher in the PALO arm in the delayed phase and overall in patients who were female, younger, or treated with cisplatin and in the delayed phase in patients who were older or treated with doxorubicin or epirubicin plus cyclophosphamide (all $p<0.05$ ).

Conclusions PALO was more effective than GRA in prophylaxis of HEC-induced nausea in the delayed phase and overall. In addition, PALO was more effective than GRA in young and female patients, who are at high risk of CINV, both in the delayed phase and overall.

Keywords $5-\mathrm{HT}_{3}$ receptor antagonist $\cdot$ Palonosetron . Chemotherapy-induced nausea and vomiting $\cdot$ Highly emetic chemotherapy $\cdot$ Antiemetics
5 Bioscience Medical Research Centre, Niigata University Medical and Dental Hospital, Niigata, Japan

6 Department of Breast Oncology, Gunma Cancer Centre, Gunma, Japan

7 Department of Thoracic Oncology, Saitama Cancer Centre, Saitama, Japan

8 Department of Breast Oncology, Saitama Cancer Centre, Saitama, Japan

9 Department of Respiratory Medicine, National Hospital Organization Nagoya Medical Centre, Aichi, Japan

10 Division of Respiratory Medicine, Kanagawa Cardiovascular and Respiratory Centre, Kanagawa, Japan 


\section{Introduction}

Chemotherapy-induced nausea and vomiting (CINV) causes distress in cancer patients and reduces their quality of life $[1,2]$. The prophylaxis of CINV has greatly improved since the appearance of the 5-hydroxytryptamine $3\left(5-\mathrm{HT}_{3}\right)$ receptor antagonists (RAs) $[3,4]$ and the neurokinin $1\left(\mathrm{NK}_{1}\right) \mathrm{RA}$ aprepitant [4-6]. However, the prophylaxis of CINV is often suboptimal [7]. If appropriate antiemetic therapy is not provided, $70-80 \%$ of patients receiving emetogenic chemotherapy will experience CINV [8]. Thus, the effective prophylaxis of CINV is a key aspect of patient care.

The current recommended standard of care (SoC) for CINV in patients receiving highly emetogenic chemotherapy (HEC) is dexamethasone plus aprepitant and a $5-\mathrm{HT}_{3}$ RA. For moderately emetogenic chemotherapy (MEC), the recommended SoC is dexamethasone and a $5-\mathrm{HT}_{3} \mathrm{RA}$ with or without aprepitant, as recommended by a number of guidelines [9-13]. Although these guidelines are widely available, their use in clinical practice remains suboptimal [14]. In addition, first-generation 5- $\mathrm{HT}_{3} \mathrm{RAs}$, such as ondansetron and granisetron (GRA), are less effective for the treatment of CINV in the delayed phase than in the acute phase $[4,15,16]$. There is therefore an unmet need for more effective therapies to control CINV, which has led to the development of new-generation $5-\mathrm{HT}_{3}$ RAs such as palonosetron (PALO).

PALO has a longer half-life, more potent binding, and unique molecular interactions with the $5-\mathrm{HT}_{3}$ receptor in comparison with the first-generation $5-\mathrm{HT}_{3} \mathrm{RAs}$ [4]. PALO allosterically binds to the $5-\mathrm{HT}_{3}$ receptors with positive cooperativity, which most likely triggers the internalization of these receptors, leading to persistent inhibition of their function [4]. In addition, PALO is able to inhibit $5-\mathrm{HT}_{3} / \mathrm{NK}_{1}$ receptor signaling crosstalk, mediating the prophylaxis of delayed CINV in contradistinction to first-generation 5- $\mathrm{HT}_{3}$ RAs [4]. It has shown efficacy in the prophylaxis of CINV in the acute and delayed phases as well as overall in a number of clinical studies [17]. PALO has also been shown to be more effective than dolasetron [18] and ondansetron [19] in patients receiving MEC and more effective than ondansetron [20] in patients receiving HEC. Additionally, a recent retrospective study in almost 10, 000 patients with breast or lung cancer treated with carboplatin or cisplatin showed that patients initiated and maintained on PALO had a significantly lower risk of CINV than patients receiving first-generation $5-\mathrm{HT}_{3}$ RAs [21]. In a comparative phase 3 study of single-dose PALO and GRA, both administered with dexamethasone, involving 1114 Japanese patients receiving HEC, Saito et al. found that PALO was non-inferior to GRA for the control of CINV in the acute phase and superior to GRA in the delayed phase [22].

When evaluating treatments to control CINV, risk factors for CINV should be taken into consideration. The efficacy of CINV prophylaxis can be influenced by the chemotherapeutic regimen and the patient's age, sex, and smoking history $[23,24]$. Although a number of studies found that the efficacy of CINV prophylaxis was not affected by age [25-27], other studies reported contrasting results. Specifically, in women being treated for chemotherapy and receiving the $5-\mathrm{HT}_{3} \mathrm{RA}$ ondansetron combined with dexamethasone, acute CINV was better controlled in older patients ( $>45$ years) and in patients receiving noncisplatin-containing chemotherapy [28]. The 5- $\mathrm{HT}_{3} \mathrm{RA}$ GRA has also been reported to be more effective in elderly patients [29]. A recent study aiming to identify CINV risk factors showed that non-habitual alcohol intake and younger age ( $<55$ years) were risk factors for acute CINV and that female sex was a risk factor for both acute and delayed CINV [24].

In trials evaluating CINV treatments, to assess the occurrence of nausea is also important. Nausea is reported to have a greater negative effect on daily life than vomiting [1] and remains one of the most feared chemotherapy-related adverse events [8]. The challenges of controlling chemotherapy-induced nausea are greater than those for chemotherapy-induced vomiting, mostly because nausea is less well understood at the neurochemical level [30]. Therefore, many CINV treatments have been less successful for nausea control than for vomiting control [31,32].

In a further analysis of the Japanese comparative phase 3 study conducted by Saito et al. [22], the efficacy of PALO for the control of nausea was evaluated in the overall population and in subgroups stratified according to sex, type of chemotherapy (cisplatin or doxorubicin/ epirubicin plus cyclophosphamide [AC/EC]), and age $(<55$ or $\geq 55$ years).

\section{Patients and methods}

\section{Study design}

Details of the study design have previously been published [22] (ClinicalTrials.gov number: NCT00359567).

\section{Nausea}

Evaluation of nausea was a secondary endpoint. The proportion of patients without nausea was assessed daily (days 1-5), during the acute phase $(0-24 \mathrm{~h})$, delayed phase $(24-120 \mathrm{~h})$, and overall $(0-120 \mathrm{~h})$. In addition, the proportion of patients without nausea was assessed according to the stratification 
factors including sex, age ( $<55$ or $\geq 55$ years), and type of chemotherapy (cisplatin or AC/EC). Patient diaries were used to evaluate the degree of nausea in daily (24-h) intervals for $120 \mathrm{~h}$ after the start of chemotherapy. Nausea was defined as the feeling of being about to vomit. Nausea severity was categorized using a 4 -point Likert scale $(0=$ no nausea, $1=$ mild nausea, 2 = moderate nausea, and $3=$ severe nausea) according to the subjective assessment of each patient.

\section{Statistics}

The efficacy analyses were based on the modified intentionto-treat (ITT) cohort, which included all randomized patients who received the study drugs and HEC. The proportion of patients without nausea was assessed during the acute phase, the delayed phase, the overall study period, and at 24-h intervals throughout the $120 \mathrm{~h}$. Baseline characteristics of the modified ITT cohort were summarized descriptively. Fisher's exact test was used to analyze the proportion of patients without nausea during the acute phase, delayed phase, and overall for the comparison of treatment arms. The Wilcoxon test was used to compare the severity of nausea in each 24-h period in all patients by arm.

The proportion of patients without nausea in each phase and throughout the $120 \mathrm{~h}$ at 24-h intervals was compared by the chi-square test between the treatment arms and between subgroups stratified by sex, age, and type of chemotherapy. All statistical tests were two-tailed. Statistical significance was set at $p<0.05$. SAS software version 8.2 (SAS Institute, Inc., Cary, NC, USA) was used for all statistical analysis.

\section{Results}

\section{Baseline characteristics}

Of the 1143 patients randomized, 1119 patients were treated, 5 of whom were subsequently excluded from the efficacy analyses because of the insufficiently emetogenic chemotherapy. Thus, 1114 patients $(n=555$ in the PALO arm; $n=559$ in the GRA arm) were included in the modified ITT cohort for the efficacy analyses.

The baseline characteristics of the modified ITT cohort are shown in Table 1. The sex distribution was comparable between the two treatment arms (58.7\% [326/555 patients] in the PALO arm vs. $58.0 \%$ [324/559] in the GRA arm were female), as was the age distribution (67.7\% [376/555] vs. $68.0 \%[380 / 559] \geq 55$ years, respectively). Prior to study initiation, the majority of patients in two arms ( $>90 \%)$ were chemotherapy naive. A similar proportion of patients in both study arms received cisplatin (56.9\% [316/555] vs. $57.8 \%$ [323/559], respectively) or AC/EC (43.1\% [239/555] vs. $42.2 \%$ [236/559], respectively).
Table 1 Baseline characteristics of the modified intention-to-treat cohort

\begin{tabular}{|c|c|c|}
\hline & $\begin{array}{l}\text { Palonosetron arm } \\
(n=555)\end{array}$ & $\begin{array}{l}\text { Granisetron arm } \\
(n=559)\end{array}$ \\
\hline \multicolumn{3}{|l|}{ Gender, $n(\%)$} \\
\hline Female & $326(58.7)$ & $324(58.0)$ \\
\hline Male & $229(41.3)$ & $235(42.0)$ \\
\hline \multicolumn{3}{|l|}{ Age, years } \\
\hline Mean (SD) & $58.4(10.4)$ & $58.0(10.5)$ \\
\hline$\geq 55$ years, $n(\%)$ & $376(67.7)$ & $380(68.0)$ \\
\hline$<55$ years, $n(\%)$ & $179(32.3)$ & $179(32.0)$ \\
\hline \multicolumn{3}{|l|}{ Tumor type, n (\%) } \\
\hline Non-small cell lung cancer & $248(44.7)$ & $249(44.5)$ \\
\hline Small cell lung cancer & $47(8.5)$ & $52(9.3)$ \\
\hline Breast cancer & $239(43.1)$ & $236(42.2)$ \\
\hline Others & $21(3.8)$ & $22(3.9)$ \\
\hline \multicolumn{3}{|l|}{ Chemotherapy, $n(\%)$} \\
\hline Cisplatin & $316(56.9)$ & $323(57.8)$ \\
\hline $\mathrm{AC} / \mathrm{EC}$ & $239(43.1)$ & $236(42.2)$ \\
\hline \multicolumn{3}{|l|}{ Previous chemotherapy, $n(\%)$} \\
\hline Naive & $519(93.5)$ & $516(92.3)$ \\
\hline Non-naive & $36(6.5)$ & $43(7.7)$ \\
\hline
\end{tabular}

$A C / E C$ doxorubicin or epirubicin with cyclophosphamide, $S D$ standard deviation

\section{Nausea control}

On day 1 , in the acute phase, the proportion of patients without nausea was similar in the PALO arm (58.7\% [326/555]) and in the GRA arm (59.9\% [335/559]). However, there was a significantly higher proportion of patients without nausea in the delayed phase $(p=0.0002)$ and overall $(p=0.0117)$ in the PALO arm than in the GRA arm (Fig. 1a). When assessed daily, the proportion of patients without nausea was significantly higher in the PALO arm than in the GRA arm on days 2, 3, 4, and 5 (all $p<0.05$ ) (Fig. 1b).

Severity of nausea over time was analyzed for both treatment arms (Fig. 2). The proportion of patients who experienced severe nausea was similar in two arms on day 1 (6.1\% [34/555] vs. $5.9 \%$ [33/559]), but was lower in the PALO arm on day $2(4.3 \%$ [24/553] vs. $6.4 \%$ [36/559]), day $3(2.7 \%[15 / 552]$ vs. $4.7 \%$ [26/559]), day $4(2.9 \%$ [16/552] vs. $7.2 \%$ [40/559]), and day 5 (1.6\% [9/551] vs. $5.0 \%$ [28/559]). The severity of nausea was significantly lower in the PALO arm during the 24-48 $\mathrm{h}(p=0.0180)$, 48-72 h $(p=0.0043), 72-96 \mathrm{~h}(p=0.0005)$, and $96-120 \mathrm{~h}$ $(p=0.0030)$ periods than in the GRA arm.

The proportion of patients without nausea was also assessed according to the stratification factors including sex, age, and chemotherapy regimen. In male patients, no significant difference was noted between two arms in any phase. In 
Fig. 1 Proportion of patients without nausea (a) in each phase and (b) on each day for each treatment arm. ${ }^{*} p$ values determined by Fisher's exact test, $* * p<0.05$ (chi-square test)
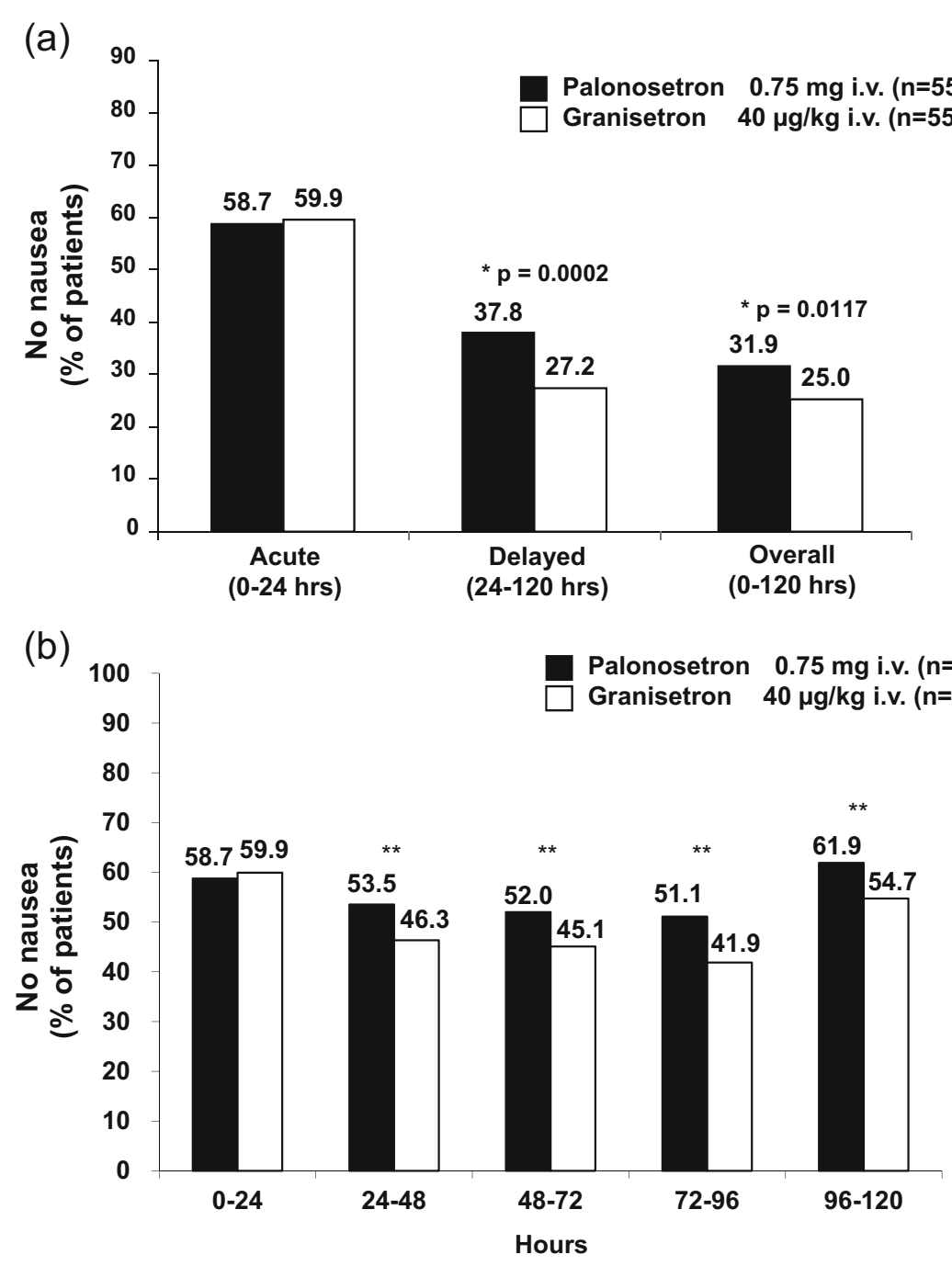

the acute phase, the proportion of patients without nausea was slightly lower in the PALO arm than in the GRA arm $(76.4 \%$ [175/229] vs. $79.1 \%$ [186/235]), whereas it was slightly higher in the delayed phase (40.6\% [93/229] vs. $35.3 \%$ [83/235]) and overall (38.9\% [89/229] vs. $34.5 \%$ [81/235]) (Fig. 3). In female patients, No significant difference was noted between the treatment arms in the acute phase $(46.3 \%$ [151/326] vs. $46.0 \%$ [149/324]), but a significant difference was noted in the delayed phase (36.1\% [117/ 324] vs. $21.3 \%$ [69/324]) and overall (27.0\% [88/326] vs. $18.2 \%$ [59/324]), with a higher proportion of patients without nausea in the PALO arm than in the GRA arm $(p<0.05)$ (Fig. 3).

In the $<55$ and $\geq 55$ years age groups, the proportion of patients without nausea was similar between the two treatment arms in the acute phase ( $\geq 55$ years, $69.1 \%$ [260/376] vs. $68.4 \%$ [260/380]; <55 years, $36.9 \%$ [66/179] vs. $41.9 \%$ [75/179]) (Fig. 4). However, in both age groups, the proportion of patients without nausea was higher in the PALO arm than in the GRA arm in the delayed phase $(\geq 55,39.2 \%$ [147/375] Vs. $30.8 \%[117 / 380] ;<55,35.4 \%$, [63/178] vs. $19.6 \%$ [35/179]) and overall (35.4\% [133/376] vs. $29.2 \%[111 / 380] ;<55,24.6 \%$ [44/179] vs. $16.2 \%$ [29/179]) (Fig. 4). The differences were significant in the delayed phase and overall in younger patients and in the delayed phase in older patients (all $p<0.05$ ).

In the cisplatin and $\mathrm{AC} / \mathrm{EC}$ chemotherapy groups, the proportion of patients without nausea was similar in the PALO and GRA arms in the acute phase (68.7\% [217/316] vs. $70.3 \%$ [227/323] for cisplatin; $45.6 \%$ [109/239] vs. $45.8 \%$ [108/236] for AC/EC) (Fig. 5a). In the delayed phase and overall, the proportion of patients without nausea was higher in the PALO arm (37.0\% [117/316] and 34.8\% [110/316] for cisplatin; $39.2 \%$ [93/237] and 28.0\% [67/239] for AC/EC) than in the GRA arm (27.9\% [90/323] and 27.2\% [88/323] for cisplatin; $26.3 \%$ [62/236] and $22.0 \%$ [52/236] for $\mathrm{AC} /$ EC) (Fig. 5a). The differences were significant in the delayed phase and overall in the cisplatin chemotherapy group 
Fig. 2 Severity of nausea over time for both treatment arms. ${ }^{*} p<0.05$ (Wilcoxon test). PALO, palonosetron; $G R A$, granisetron

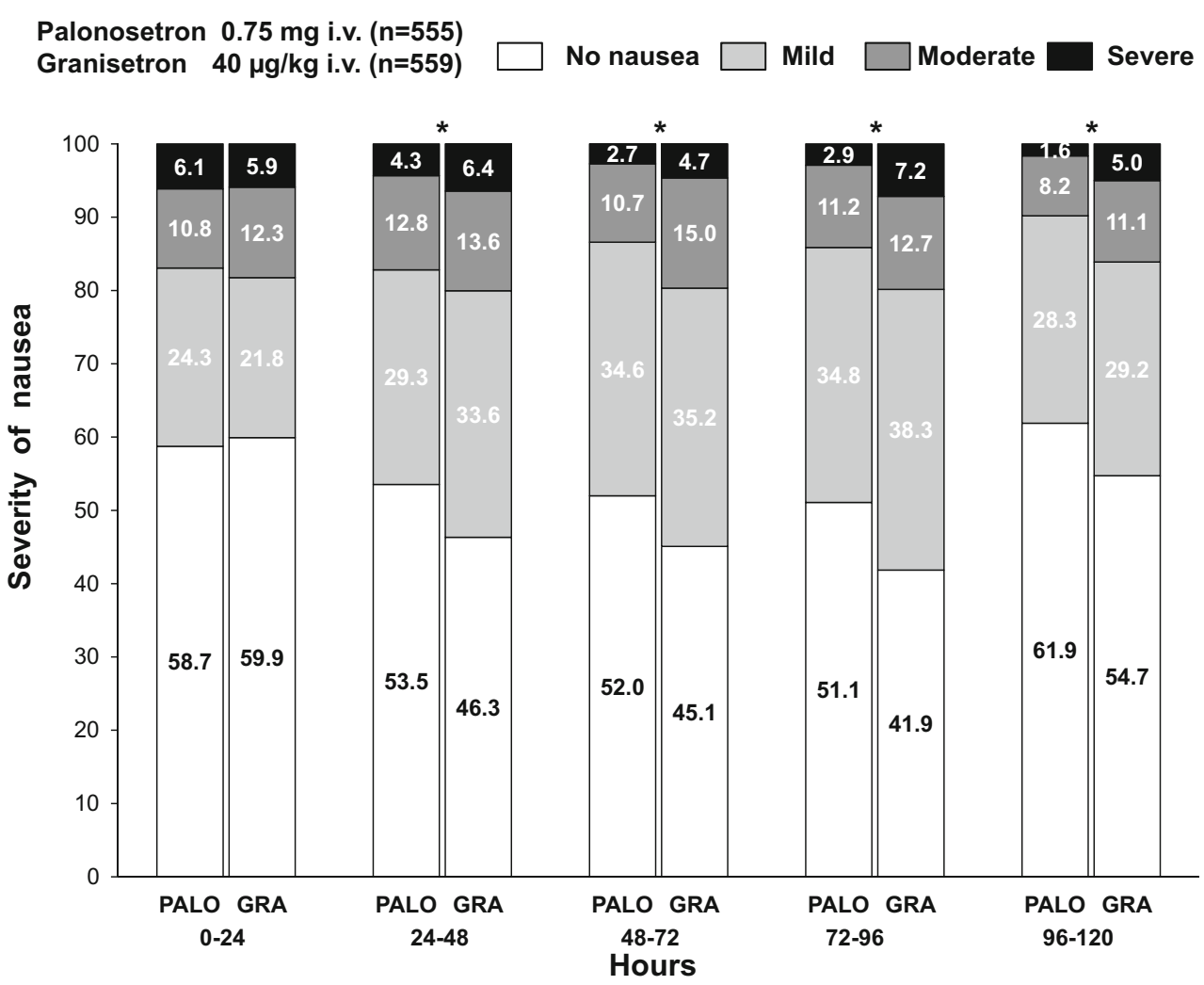

and in the delayed phase in the $\mathrm{AC} / \mathrm{EC}$ chemotherapy group (all $p<0.05$ ).

In patients stratified by chemotherapy, the proportion of patients without nausea was also analyzed daily (Fig. 5b). In the cisplatin-treated group, the proportion of patients without nausea was similar for both PALO and GRA arms on days 1, 2, and 3 (68.7\% [217/316],
$55.1 \%[174 / 316], 52.2 \%[165 / 316]$ vs. $70.3 \%[227 /$ 323], $52.3 \%$ [169/323], $48.0 \%$ [155/323]), but was significantly higher in the PALO arm on day $4(49.1 \%[155 /$ $316]$ vs. $39.6 \%[128 / 323] ; p<0.05)$ and day $5(56.5 \%[178 /$ $315]$ vs. $44.0 \%[142 / 323] ; p<0.05)$. In the AC/EC-treated group, the proportion of patients without nausea was similar with PALO and GRA treatments on day 1 (45.6 \% [109/239]

\section{Male}

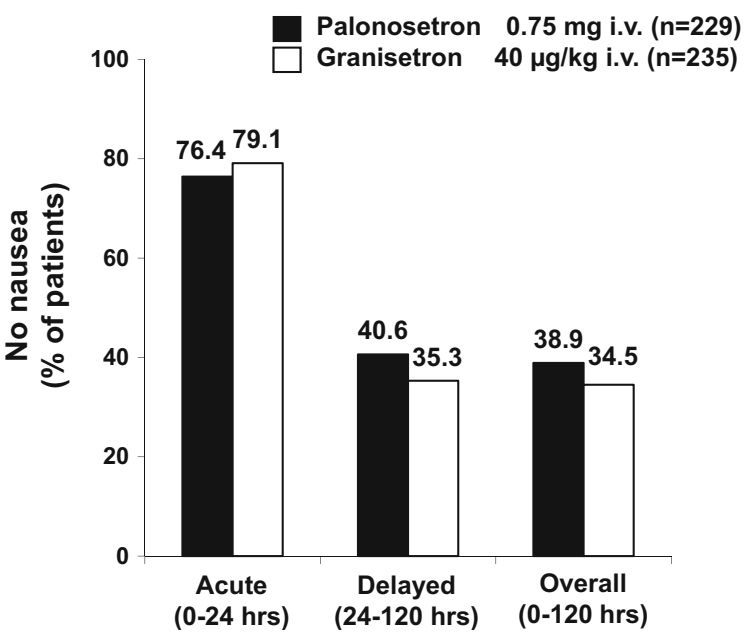

\section{Female}

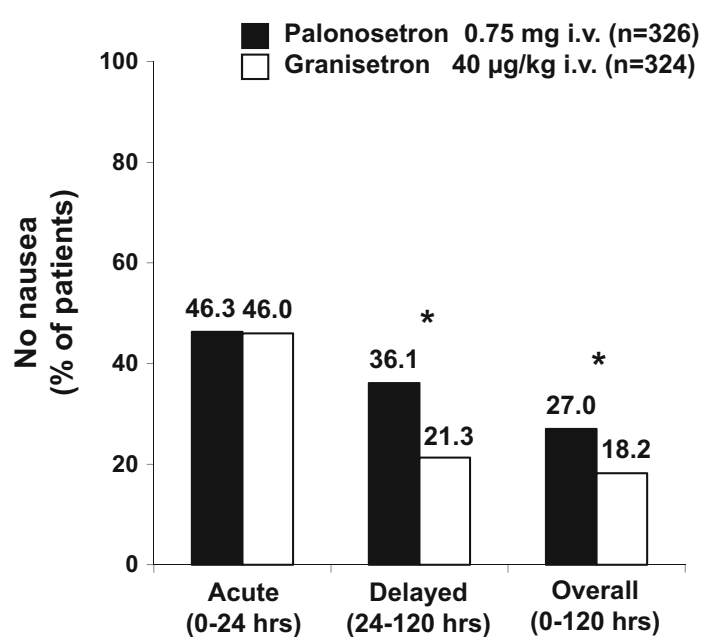

Fig. 3 Proportion of patients stratified by sex without nausea in each phase. ${ }^{*} p<0.05$ (chi-square test) 
$<55$ years

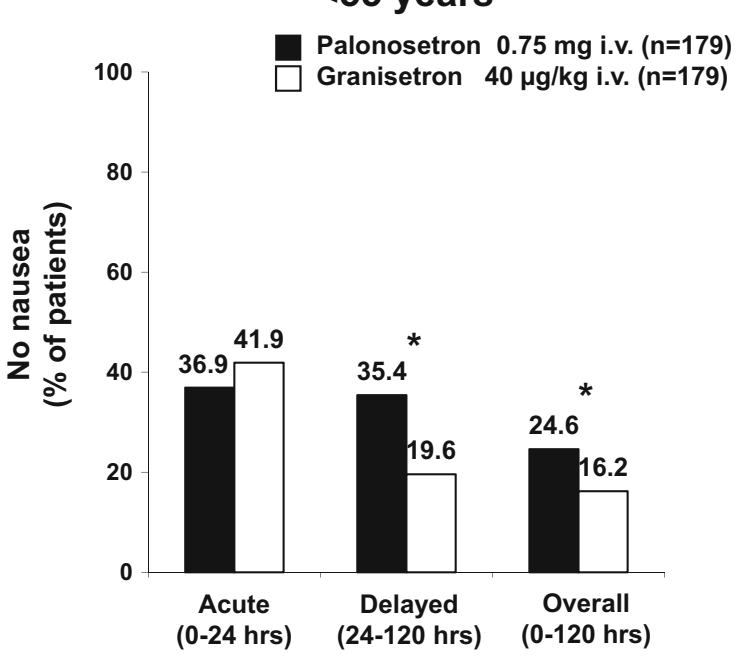

\section{$\geq 55$ years}

Palonosetron $0.75 \mathrm{mg}$ i.v. $(\mathrm{n}=376)$

Granisetron $40 \mu \mathrm{g} / \mathrm{kg}$ i.v. $(\mathrm{n}=380)$

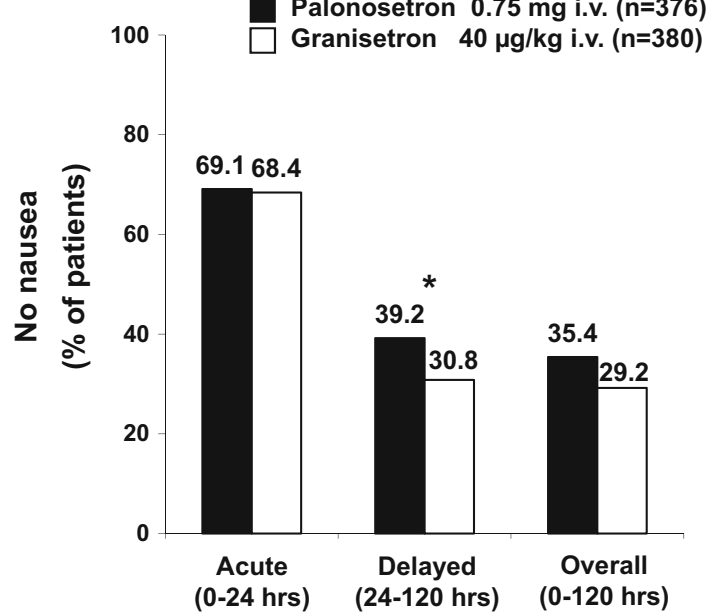

Fig. 4 Proportion of patients stratified by age without nausea in each phase. ${ }^{*} p<0.05$ (chi-square test)

vs. $45.8 \%$ [108/236]) and day $5(69.1 \%$ [163/236] vs. $69.5 \%$ [164/236]), but was higher with PALO treatment on days 2, 3, and 4 (51.5 \% [122/237], $51.7 \%$ [122/236], $53.8 \%$ [127/236] vs. $38.1 \%$ [90/236], $41.1 \%$ [97/236], $44.9 \%$ [106/236]). This difference was significant on days 2 and 3 (both $p<0.05$ ) (Fig. 5b).

(a)

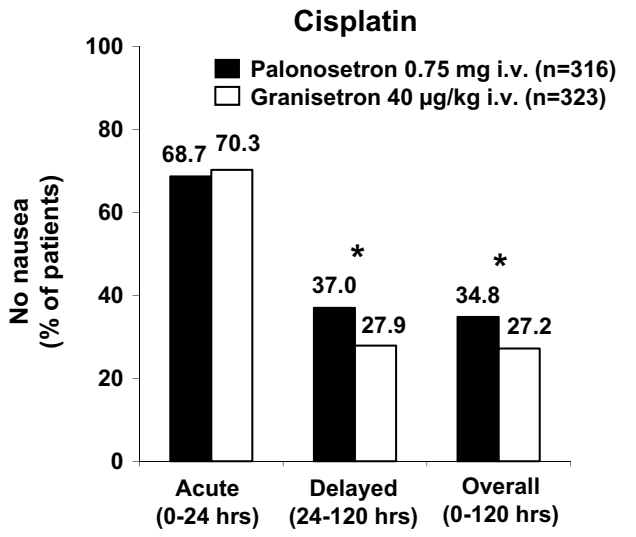

(b)

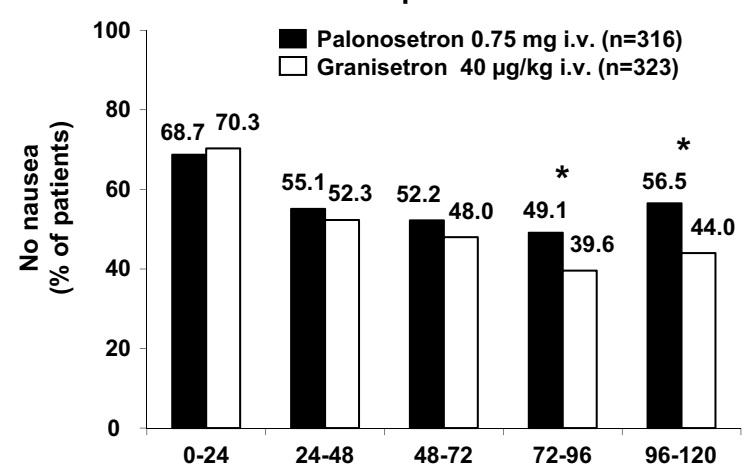

\section{Discussion}

In this post hoc analysis of Saito et al.'s phase 3 study in Japanese patients receiving HEC [22], PALO achieved significantly better control of nausea than GRA in the overall study population during the delayed phase, overall, and during
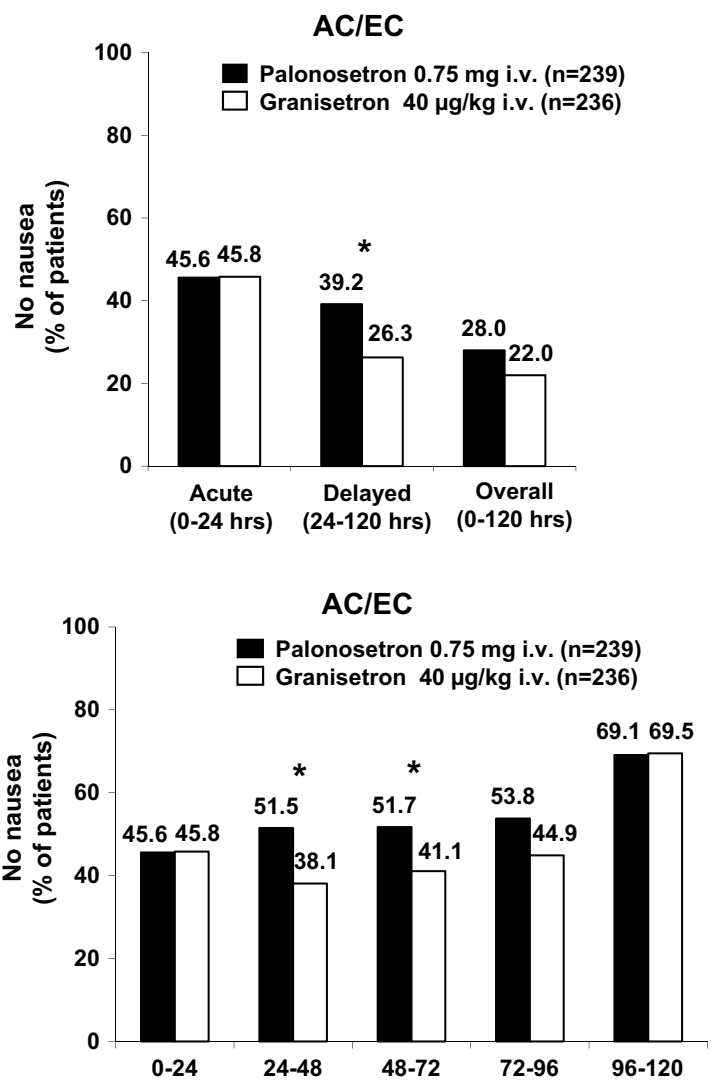

Fig. 5 Proportion of patients stratified by chemotherapy treatment without nausea a in each phase and $\mathbf{b}$ in each 24 -h interval. ${ }^{*} p<0.05$ (chi-square test). Cisplatin or doxorubicin/epirubicin plus cyclophosphamide(AC/EC) 
each day of the delayed phase. When evaluated by subgroups for age, sex, and type of chemotherapy, the proportion of "nausea-free" patients in the delayed phase was higher with PALO treatment than with GRA treatment, and the difference was significant in female patients, both age groups, and both chemotherapy groups. It is of particular interest that PALO protects against nausea in the delayed phase in female patients and in both age groups because a recent pooled analysis of two phase 2 trials and one phase 3 trial of PALO showed that younger age $(<55$ years) is a risk factor for acute CINV and that female sex is a risk factor for both acute and delayed CINV [24].

Treatment outcome and survival are reported to be associated with the relative dose intensity of chemotherapy [33, 34]. Therefore, when administering chemotherapy, it is also necessary to give appropriate supportive care treatment to achieve maximal benefit, with consideration of the related side effects. The most dreaded adverse effects of chemotherapy that have long been recognized are nausea and vomiting [35]. In a recent multicenter, prospective, observational study in Japan, it was reported that nausea and vomiting during the acute phase were relatively well controlled but the incidence of nausea during the delayed phase was high in the patients receiving HEC and MEC. Such adverse events lead to loss of appetite, which is related to poor treatment outcomes and short survival [36]. Also, this study reported that female sex and age were risk factors for acute and delayed nausea. Cancer patients tend to report symptoms, such as nausea and vomiting, earlier and more frequently than clinicians. In addition, patients' reports were found to have a higher concordance than clinicians' reports with overall health status $[37,38]$. The incidence of CINV may also be considerably underestimated by healthcare providers, particularly in the delayed phase [39]. The incidence of delayed CINV was underestimated by $75 \%$ of physicians and nurses after the treatment of HEC and MEC. Delayed nausea in particular was underestimated by 21 percentage points after HEC and 28 percentage points after MEC [37]. Delayed nausea and vomiting are still important targets in the development of improved antiemetics. Effective treatments are needed especially for nausea, as this adverse event reduces cancer patients' quality of life considerably [1]. However, in spite of advanced understanding of the physiology of CINV, the ability to treat nausea remains poor as its neurochemistry seems much more complex [30].

A recent trial reported that PALO was as effective as GRA in the prophylaxis of delayed nausea [40]. However, comparison between their study and ours is complex due to differences in experimental setup and data reporting [41]. The findings from our study are consistent with those from several phase 3 clinical trials showing that PALO has superior efficacy in nausea control in comparison with first-generation $5-\mathrm{HT}_{3} \mathrm{RAs}$
[18-20, 42]. In the MEC setting, it has been reported that the proportion of patients who experience no nausea was significantly greater in those receiving PALO than in those receiving dolasetron on days 2 and 3 of treatment [18]. Accordingly, another phase 3 study showed better control of nausea with PALO than with ondansetron on days 3,4 , and 5 of treatment [19]. In the HEC setting, Aapro et al. also reported higher protection from acute nausea in patients treated with PALO than in those treated with ondansetron, although differences between the treatment arms did not reach statistical significance [20].

A recent meta-analysis of 16 randomized controlled trials showed that, in general, PALO was statistically superior to first-generation $5-\mathrm{HT}_{3} \mathrm{RAs}$ in terms of complete response, complete control, without emesis, and without nausea. Particularly, in both the delayed phase and overall in the studies including corticosteroid, the proportion of patients who experience no nausea was significantly higher in those receiving PALO compared with those receiving first-generation $5-\mathrm{HT}_{3}$ RAs [43]. Taken together, the great majority of studies suggested better nausea control outcomes with PALO during the delayed phase than with first-generation $5-\mathrm{HT}_{3}$ RAs. Furthermore, Aogi et al. reported that PALO plus dexamethasone was effective for the control of nausea in multiple cycles of HEC [44].

In conclusion, in this study, PALO was found to be more effective than GRA in prophylaxis of nausea induced by HEC, both in the delayed phase and overall. Subgroup analysis showed that PALO was more effective than GRA in young patients and female patients, who are at high risk of CINV, both in the delayed phase and overall.

Acknowledgments The trial was funded by Taiho Pharmaceutical, Tokyo, Japan. Editorial and medical writing assistance was provided by Anna Hooijkaas, PhD, TRM Oncology, the Hague, the Netherlands, and funded by Helsinn Healthcare SA, Lugano, Switzerland. Taiho Pharmaceutical provided a full review of the article.

Compliance with ethical standards The study was conducted in accordance with the Declaration of Helsinki. The study protocol was approved by the institutional review board at each study site before imitation of the study. Written informed consent was obtained from each participant before enrollment.

Conflicts of interest $\mathrm{KK}$ has received remuneration from Taiho Pharmaceutical and Chugai Pharmaceutical and funding from Taiho Pharmaceutical. MS has received remuneration from Taiho Pharmaceutical, Chugai Pharmaceutical, Ono Pharmaceutical, and Helsinn Healthcare SA. KA has received remuneration from Taiho Pharmaceutical, Chugai Pharmaceutical, AstraZeneca, Eizai, Ono Pharmaceutical, Otsuka Pharmaceutical, Sanofi, Daiichi Sankyo Company, Nihon Medi-Physics, and Becton Dickinson and Company. IS has received remuneration from Taiho Pharmaceutical and Chugai Pharmaceutical. HY has received remuneration and funding from Taiho 
Pharmaceutical, Chugai Pharmaceutical, and Ono Pharmaceutical. YY has received remuneration from Taiho Pharmaceutical and Chugai Pharmaceutical. HS has received remuneration and funding from Taiho Pharmaceutical, Chugai Pharmaceutical, Eli Lily, and Ono Pharmaceutical and funding from MSD and Bristol-Myers Squibb. KI has received remuneration and funding from Taiho Pharmaceutical and funding from Novartis, Chugai Pharmaceutical, Daiichi Sankyo Company, Puma Biotechnology, and Nippon Kayaku. CK and TO have no conflicts of interest to declare.

Open Access This article is distributed under the terms of the Creative Commons Attribution-NonCommercial 4.0 International License (http://creativecommons.org/licenses/by-nc/4.0/), which permits any noncommercial use, distribution, and reproduction in any medium, provided you give appropriate credit to the original author(s) and the source, provide a link to the Creative Commons license, and indicate if changes were made.

\section{References}

1. Bloechl-Daum B, Deuson RR, Mavros P, Hansen M, Herrstedt J (2006) Delayed nausea and vomiting continue to reduce patients' quality of life after highly and moderately emetogenic chemotherapy despite antiemetic treatment. J Clin Oncol 24(27):4472-4478. doi:10.1200/jco.2006.05.6382

2. Hilarius DL, Kloeg PH, van der Wall E, van den Heuvel JJ, Gundy CM, Aaronson NK (2012) Chemotherapy-induced nausea and vomiting in daily clinical practice: a community hospital-based study. Support Care Cancer 20(1):107-117. doi:10.1007/s00520010-1073-9

3. Hesketh PJ (2000) Comparative review of 5-HT3 receptor antagonists in the treatment of acute chemotherapy-induced nausea and vomiting. Cancer Invest 18(2):163-173

4. Rojas C, Slusher BS (2012) Pharmacological mechanisms of 5HT(3) and tachykinin NK(1) receptor antagonism to prevent chemotherapy-induced nausea and vomiting. Eur J Pharmacol 684(1-3):1-7. doi:10.1016/j.ejphar.2012.01.046

5. Dando TM, Perry CM (2004) Aprepitant: a review of its use in the prevention of chemotherapy-induced nausea and vomiting. Drugs 64(7):777-794

6. Reddy GK, Gralla RJ, Hesketh PJ (2006) Novel neurokinin-1 antagonists as antiemetics for the treatment of chemotherapy-induced emesis. Support Cancer Ther 3(3):140-142. doi:10.3816/SCT. 2006.n.011

7. Wickham R (2012) Evolving treatment paradigms for chemotherapy-induced nausea and vomiting. Cancer Control 19(2 Suppl):3-9

8. Feyer P, Jordan K (2011) Update and new trends in antiemetic therapy: the continuing need for novel therapies. Ann Oncol 22(1):30-38. doi:10.1093/annonc/mdq600

9. Basch E, Hesketh PJ, Kris MG, Prestrud AA, Temin S, Lyman GH (2011) Antiemetics: american society of clinical oncology clinical practice guideline update. J Oncol Pract 7(6):395-398. doi:10.1200/jop.2011.000397

10. NCCN Clinical Practice Guidelines in Oncology ( $\mathrm{NCCN}$ Guidelines $\left.{ }^{\circledR}\right)$ Antiemesis. Version 1.2015. (2015) National Comprehensive Cancer Network. http://www.ncen.org/ professionals/physician_gls/f_guidelines.asp. Accessed 1 Apr 2015

11. Roila F, Herrstedt J, Aapro M, Gralla RJ, Einhorn LH, Ballatori E, Bria E, Clark-Snow RA, Espersen BT, Feyer P, Grunberg SM,
Hesketh PJ, Jordan K, Kris MG, Maranzano E, Molassiotis A, Morrow G, Olver I, Rapoport BL, Rittenberg C, Saito M, Tonato M, Warr D (2010) Guideline update for MASCC and ESMO in the prevention of chemotherapy- and radiotherapy-induced nausea and vomiting: results of the Perugia consensus conference. Ann Oncol 21(Suppl 5):v232-v243. doi:10.1093/annonc/mdq194

12. Roila F, Herrstedt J, Gralla RJ, Tonato M (2011) Prevention of chemotherapy- and radiotherapy-induced nausea and vomiting: guideline update and results of the Perugia consensus conference. Support Care Cancer 19(Suppl 1):S63-S65. doi:10.1007/s00520010-1044-1

13. Wickham R (2010) Best practice management of CINV in oncology patients: II. Antiemetic guidelines and rationale for use. J Support Oncol 8(2 Suppl 1):10-15

14. Aapro M, Molassiotis A, Dicato M, Pelaez I, Rodriguez-Lescure A, Pastorelli D, Ma L, Burke T, Gu A, Gascon P, Roila F (2012) The effect of guideline-consistent antiemetic therapy on chemotherapyinduced nausea and vomiting (CINV): the Pan European Emesis Registry (PEER). Ann Oncol 23(8):1986-1992. doi:10.1093/ annonc/mds021

15. Geling O, Eichler HG (2005) Should 5-hydroxytryptamine-3 receptor antagonists be administered beyond 24 hours after chemotherapy to prevent delayed emesis? Systematic re-evaluation of clinical evidence and drug cost implications. J Clin Oncol 23(6):1289-1294. doi:10.1200/jco.2005.04.022

16. Hesketh PJ, Van Belle S, Aapro M, Tattersall FD, Naylor RJ, Hargreaves R, Carides AD, Evans JK, Horgan KJ (2003) Differential involvement of neurotransmitters through the time course of cisplatin-induced emesis as revealed by therapy with specific receptor antagonists. Eur J Cancer 39(8):1074-1080

17. Likun Z, Xiang J, Yi B, Xin D, Tao ZL (2011) A systematic review and meta-analysis of intravenous palonosetron in the prevention of chemotherapy-induced nausea and vomiting in adults. Oncologist 16(2):207-216. doi:10.1634/theoncologist.2010-0198

18. Eisenberg P, Figueroa-Vadillo J, Zamora R, Charu V, Hajdenberg J, Cartmell A, Macciocchi A, Grunberg S (2003) Improved prevention of moderately emetogenic chemotherapy-induced nausea and vomiting with palonosetron, a pharmacologically novel 5-HT3 receptor antagonist: results of a phase III, single-dose trial versus dolasetron. Cancer 98(11):2473-2482. doi:10.1002/cncr.11817

19. Gralla R, Lichinitser M, Van Der Vegt S, Sleeboom H, Mezger J, Peschel C, Tonini G, Labianca R, Macciocchi A, Aapro M (2003) Palonosetron improves prevention of chemotherapy-induced nausea and vomiting following moderately emetogenic chemotherapy: results of a double-blind randomized phase III trial comparing single doses of palonosetron with ondansetron. Ann Oncol 14(10): 1570-1577

20. Aapro MS, Grunberg SM, Manikhas GM, Olivares G, Suarez T, Tjulandin SA, Bertoli LF, Yunus F, Morrica B, Lordick F, Macciocchi A (2006) A phase III, double-blind, randomized trial of palonosetron compared with ondansetron in preventing chemotherapy-induced nausea and vomiting following highly emetogenic chemotherapy. Ann Oncol 17(9):1441-1449. doi:10. 1093/annonc/mdl137

21. Lin SJ, Hatoum HT, Buchner D, Cox D, Balu S (2012) Impact of 5HT3 receptor antagonists on chemotherapy-induced nausea and vomiting: a retrospective cohort study. BMC Health Serv Res 12:215. doi:10.1186/1472-6963-12-215

22. Saito M, Aogi K, Sekine I, Yoshizawa H, Yanagita Y, Sakai H, Inoue K, Kitagawa C, Ogura T, Mitsuhashi S (2009) Palonosetron plus dexamethasone versus granisetron plus dexamethasone for prevention of nausea and vomiting during chemotherapy: a double-blind, double-dummy, randomised, comparative phase III trial. Lancet Oncol 10(2):115-124. doi:10.1016/s14702045(08)70313-9 
23. Doherty KM (1999) Closing the gap in prophylactic antiemetic therapy: patient factors in calculating the emetogenic potential of chemotherapy. Clin J Oncol Nurs 3(3):113-119

24. Sekine I, Segawa Y, Kubota K, Saeki T (2013) Risk factors of chemotherapy-induced nausea and vomiting: index for personalized antiemetic prophylaxis. Cancer Sci 104(6):711-717. doi:10. $1111 /$ cas. 12146

25. Massa E, Astara G, Madeddu C, Dessi M, Loi C, Lepori S, Mantovani G (2009) Palonosetron plus dexamethasone effectively prevents acute and delayed chemotherapy-induced nausea and vomiting following highly or moderately emetogenic chemotherapy in pre-treated patients who have failed to respond to a previous antiemetic treatment: comparison between elderly and non-elderly patient response. Crit Rev Oncol Hematol 70(1):83-91. doi:10. 1016/j.critrevonc.2008.07.002

26. Ruff P, Paska W, Goedhals L, Pouillart P, Riviere A, Vorobiof D, Bloch B, Jones A, Martin C, Brunet R et al (1994) Ondansetron compared with granisetron in the prophylaxis of cisplatin-induced acute emesis: a multicentre double-blind, randomised, parallelgroup study. The Ondansetron and Granisetron Emesis Study Group. Oncology 51(1):113-118

27. Italian Group of Antiemetic Research (1995) Ondansetron versus granisetron, both combined with dexamethasone, in the prevention of cisplatin-induced emesis. Ann Oncol 6(8):805-810

28. Pradermdee P, Manusirivithaya S, Tangjitgamol S, Thavaramara T, Sukwattana P (2006) Antiemetic effect of ondansetron and dexamethasone in gynecologic malignant patients receiving chemotherapy. J Med Assoc Thai 89(Suppl 4):S29-S36

29. Kleisbauer JP, Garcia-Giron C, Antimi M, Azevedo MC, Balmes H, Massuti-Sureda B, Contu A, Luque A, Pellier P (1998) Granisetron plus methylprednisolone for the control of high-dose cisplatin-induced emesis. Anticancer Drugs 9(5):387-392

30. Sanger GJ, Andrews PL (2006) Treatment of nausea and vomiting: gaps in our knowledge. Auton Neurosci 129(1-2):3-16. doi:10. 1016/j.autneu.2006.07.009

31. Warr DG, Hesketh PJ, Gralla RJ, Muss HB, Herrstedt J, Eisenberg PD, Raftopoulos H, Grunberg SM, Gabriel M, Rodgers A, Bohidar N, Klinger G, Hustad CM, Horgan KJ, Skobieranda F (2005) Efficacy and tolerability of aprepitant for the prevention of chemotherapy-induced nausea and vomiting in patients with breast cancer after moderately emetogenic chemotherapy. J Clin Oncol 23(12):2822-2830. doi:10.1200/jco.2005.09.050

32. Yeo W, Mo FK, Suen JJ, Ho WM, Chan SL, Lau W, Koh J, Yeung WK, Kwan WH, Lee KK, Mok TS, Poon AN, Lam KC, Hui EK, Zee B (2009) A randomized study of aprepitant, ondansetron and dexamethasone for chemotherapy-induced nausea and vomiting in Chinese breast cancer patients receiving moderately emetogenic chemotherapy. Breast Cancer Res Treat 113(3):529-535. doi:10. 1007/s10549-008-9957-9

33. Bonadonna G, Valagussa P, Moliterni A, Zambetti M, Brambilla C (1995) Adjuvant cyclophosphamide, methotrexate, and fluorouracil in node-positive breast cancer: the results of 20 years of follow-up. N Engl J Med 332(14):901-906. doi:10.1056/ nejm199504063321401

34. Epelbaum R, Faraggi D, Ben-Arie Y, Ben-Shahar M, Haim N, Ron Y, Robinson E, Cohen Y (1990) Survival of diffuse large cell lymphoma. A multivariate analysis including dose intensity variables. Cancer 66(6):1124-1129

35. Sun CC, Bodurka DC, Weaver CB, Rasu R, Wolf JK, Bevers MW, Smith JA, Wharton JT, Rubenstein EB (2005) Rankings and symptom assessments of side effects from chemotherapy: insights from experienced patients with ovarian cancer. Support Care Cancer 13(4):219-227. doi:10.1007/s00520-004-0710-6

36. Tamura K, Aiba K, Saeki T, Nakanishi Y, Kamura T, Baba H, Yoshida K, Yamamoto N, Kitagawa Y, Maehara Y, Shimokawa M, Hirata K, Kitajima M (2015) Testing the effectiveness of antiemetic guidelines: results of a prospective registry by the CINV Study Group of Japan. Int J Clin Oncol. doi:10.1007/s10147-0150786-7

37. Grunberg SM, Deuson RR, Mavros P, Geling O, Hansen M, Cruciani G, Daniele B, De Pouvourville G, Rubenstein EB, Daugaard G (2004) Incidence of chemotherapy-induced nausea and emesis after modern antiemetics. Cancer 100(10):2261-2268. doi: $10.1002 /$ cncr.20230

38. Basch E (2010) The missing voice of patients in drug-safety reporting. N Engl J Med 362(10):865-869. doi:10.1056/ NEJMp0911494

39. Grunberg S (2012) Patient-centered management of chemotherapyinduced nausea and vomiting. Cancer Control 19(2 Suppl):10-15

40. Roscoe JA, Heckler CE, Morrow GR, Mohile SG, Dakhil SR, Wade JL, Kuebler JP (2012) Prevention of delayed nausea: a University of Rochester Cancer Center Community Clinical Oncology Program study of patients receiving chemotherapy. J Clin Oncol 30(27):3389-3395. doi:10.1200/jco.2011.39.8123

41. Celio L, Aapro M (2013) Research on chemotherapy-induced nausea: back to the past for an unmet need? J Clin Oncol 31(10):13761377. doi:10.1200/jco.2012.47.2209

42. Navari RM (2010) Palonosetron for the prevention of chemotherapy-induced nausea and vomiting in patients with cancer. Future Oncol 6(7):1073-1084. doi:10.2217/fon.10.74

43. Popovic M, Warr DG, Deangelis C, Tsao M, Chan KK, Poon M, Yip C, Pulenzas N, Lam H, Zhang L, Chow E (2014) Efficacy and safety of palonosetron for the prophylaxis of chemotherapyinduced nausea and vomiting (CINV): a systematic review and meta-analysis of randomized controlled trials. Support Care Cancer 22(6):1685-1697. doi:10.1007/s00520-014-2175-6

44. Aogi K, Sakai H, Yoshizawa H, Masuda N, Katakami N, Yanagita Y, Inoue K, Kuranami M, Mizutani M, Masuda N (2012) A phase III open-label study to assess safety and efficacy of palonosetron for preventing chemotherapy-induced nausea and vomiting (CINV) in repeated cycles of emetogenic chemotherapy. Support Care Cancer 20(7):1507-1514. doi:10.1007/s00520-011-1239-0 